\title{
An interdisciplinary approach to mapping through scientific cartography, design and artistic expression
}

\author{
Joanna Gardener, ${ }^{\mathrm{a}}$ William Cartwright, ${ }^{\mathrm{b}}$ and Lesley Duxbury ${ }^{\mathrm{c}}$ \\ ${ }^{a}$ Swinburne University of Technology, Faculty of Health, Arts and Design, School of Design, Melbourne, Victoria, Australia; \\ jgardener@swin.edu.au \\ ${ }^{b}$ RMIT University, School of Science, Melbourne, Victoria, Australia \\ ${ }^{c}$ RMIT University, School of Art, Melbourne, Victoria, Australia
}

\begin{abstract}
This paper reports on the initial findings of an interdisciplinary study exploring perceptions of space and place through alternate ways of mapping. The research project aims to bring depth and meaning to places by utilising a combination of diverse influences and responses, including emotional, sensory, memory and imaginary. It investigates mapping from a designer's perspective, with further narration from both the cartographic science and fine art perspectives. It examines the role of design and artistic expression in the cartographic process, and its capacity to effect and transform the appearance, reading and meaning of the final cartographic outcome (Robinson 2010). The crossover between the cartographic sciences and the work of artists who explore space and place enables an interrogation of where these fields collide or alternatively merge, in order to challenge the definition of a map. By exploring cartography through the overlapping of the distinct fields of science and art, this study challenges and questions the tipping point of when a map ceases to be a map and becomes art.
\end{abstract}

Keywords: Mapping, Design, Art, Place, Perception, Senses

\section{Introduction}

Experience of a place apprehended through the senses, emotions and intellect, is fundamental to perception of that

place. This concept is the premise for a series of exploratory mapping exercises undertaken as part of this study. An heuristic approach has been made to this study, which relies on visual and theoretical research of maps and map making, in conjunction with my own design practice-led research to investigate the boundaries of cartography through exploratory mapping exercises. Following Rust (2007, p.69), this study utilises the 'professional and creative practices as instruments of inquiry, just as previous disciplines have developed research methods that employ their specialist skills and knowledge.' To illustrate the pivotal connection between experience of place and perception of place, the initial phase of this study was centred around a year-long project to map The Edinburgh Gardens, a 60-acre area of parkland situated in the heart of the inner suburb of North Fitzroy, just north of the city of Melbourne, Australia ${ }^{1}$

\footnotetext{
${ }^{1}$ The Edinburgh Gardens is one of a number of magnificent public gardens ringing Melbourne which were established in the 19th century (reflecting an early recognition of the benefits of maintaining green spaces in large cities). In 1883 paths were laid out and trees planted, most of which still survive today creating striking avenues throughout the park. A number of historical features still remain in the gardens today, including the Bandstand Rotunda, a War Memorial and the original Fitzroy Cricket Club Grandstand (late 19th century). There is also the Queen Victoria Statue Pedestal and remnants of the old Inner Circle Railway Line that cut
}

(Figure 1). This project has enabled recording and personally reflecting on the mapping journey over the course of a year, while experiencing the changing of seasons physically and emotionally. While this mapping exercise is still on going, the process thus far has allowed the unfurling and examination of this journey of mapping, to see how the crossover of scientific cartography and artistic expression link together at different points in the mapping process.

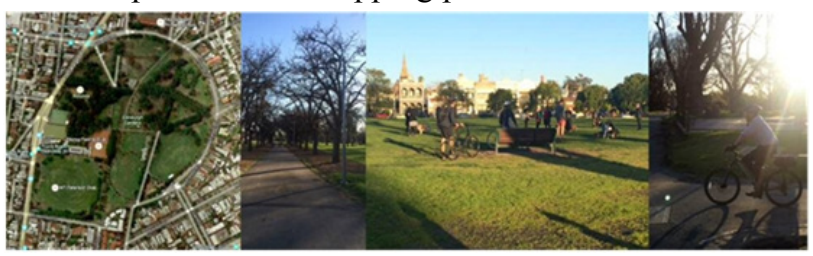

Figure 1. 1a. Edinburgh Gardens, North Fitzroy, VIC, Australia (Source: Google Maps 2016), 1b. Edinburgh Gardens footpath, Joanna Gardener, 2016, 1c. Edinburgh Gardens oval, Joanna Gardener, 2016, 1d. Edinburgh Gardens skate park and main bicycle path, Joanna Gardener, 2016

\section{Interdisciplinary approach to cartography}

In order to understand this crossover between artistic expression and cartography, it is important to step back for a moment and grasp the difference between these disciplines and what makes each of them unique. What is scientific cartography, what is art in relation to space and place and where does design fit in? Can these diverse disciplines inform each other and work together to create compelling and informed outcomes and how might this

through the gardens from 1888 to 1981, now a walking/cycling path. Place footnotes at the bottom of the page, separated from the text above it by a horizontal line 
be achieved? In short, the role of a scientific cartographer is to effectively and efficiently communicate spatial information. The cartographer generates propositions. These propositions are arguments that create awareness and understanding of space and place using data that has been recorded, selectively filtered, classified and finally represented using order and logic through a presentation of signs and codes. The cartographer's role is not to simply present the information, but to construct meaning from the information (Wood \& Fels 2008). The role of the artist is more ambiguous as artists tend to disrupt order. Artists have the ability to create their own rules, or discard them altogether. Artists can express themselves however they wish, in a freeform, that suits the outcome they want to achieve, while conveying emotion and messages from their own unique perspective and point of view. Through art we are exposed to emotions through unreal worlds that help us tackle, face, appreciate and recognise these emotions in the real world, assuming the role of a 'simulator' (Eno 2015).

Design on the other hand, is in a constant state of flux, endlessly reshaping its role as a key communicator of any given field. Depending on the intended outcome, the role of design can play a little or large part of the process of communication of an idea or set of ideas. In the instance of cartography, design plays an integral role in the mapping process, as it is through the design and aesthetics of cartography that a map is finally presented to the world through the organization and transformation of the data. It is the designer who determines the most appropriate visual or graphic representation based on the given information (Bertin \& Berg 2011). Designers ultimately have a responsibility to adhere to a brief, comply to a set of rules, while communicating their objectives much like the scientific cartographer; yet designers also have the ability to express themselves like visual artists, injecting emotion into their designs to enhance their intended message. All stages of the design process are 'conceived in high abstraction but expressed directly' (Kingsley 2015, p. 321).

Visualising the linking of these disciplines is like counterpoint in music, where the combination of two or more independent melodies are woven together creating a single '...complex conversational texture' (Staines \& Clark 2005, p. 31) while retaining their own individual identity. These disciplines share the ability to engage with individuals on different levels; each has a message to share, but what that message is, how it is interpreted, and how it is ultimately communicated is what creates the distinction between them.

\section{Linking the disciplines}

As a designer who has found herself situated at the nexus of scientific cartography and creative representation of space and place, it was necessary to employ a method of data collection that would allow for the capture and interpretation of information from the unique perspectives of these distinct disciplines.

As an experienced designer, I have found that the project, regardless of the size or scope, inevitably revolves around the brief. Through interpreting the brief designers solve problems. The brief sets the aim, direction and tone for a project. In considering the importance of the brief for my work as a designer, it begged the question, what is the equivalent to the brief when considering the work of a scientific cartographer or visual artist? For a scientific cartographer, the brief could be equated to the specifications required and for the visual artist, the brief constitutes their self- imposed parameters for imaginatively exploring a set of ideas and the use of media and materials. It is through these alternate notions of the brief that a parallel process of these distinct disciplines may converge.

The link between the cartographer's specifications and artistic imagination through the designer's brief creates the foundation of my approach to the perception of space and place. This study uses these interpretations of the brief to link the disciplines of cartography, design and art through a series of exploratory mapping exercises. These exercises interrogate the visual boundaries of cartography while demonstrating the map's potential to arouse the senses, evoke emotion and stimulate the imagination to bring depth and meaning to understanding of a place.

The two main foci of these mapping exercises:

- To explore perception of place, and the transitory nature of those perceptions.

- To discover how mapping might be used to arouse the senses, evoke experiences, recall memories or conjure up stories from the imagination.

These will be reviewed and discussed in detail throughout this study.

\section{Perception of place}

As Rebecca Solnit implies (2006), our perception of place changes depending on our experience, the emotions we attach to that experience and the memory it provides us with. It is hard to be an impartial observer of place; for example, when we feel the warmth on our skin from the midday sun, smell the sweet scent of budding flowers and hear soft laughter in the distance it general evokes positive feelings. Alternatively, when an ice cold wind whips our cheek, bringing a drenching rain that soaks our socks and sends chills up our spine, we react to the place differently, changing our experience and way in which we engage with the environment. Each individual experience leaves a lasting impression on us and inevitably our relationship to the place where the experience occurred. The overlapping of these lived experiences of places, the memories attached to these experiences and personal identity, build individual narratives, deepening our understanding of space and place (Gieseking 2013).

Sébastien Caquard examines the relationship between maps and narratives, proposing that maps have the ability to be a 'storytelling stimulator' (2011). This storytelling capacity of maps allows us to consider our relationships with places, and the map's ability to shape our perceptions of place (Caquard 2015). 
Artists have long utilised the map as a storytelling platform, a method to explore their understandings and relation- ship to space and place. However, for many artists this exploration of space and place extends beyond the map as they find alternate ways to explore and engage with the world around them. The way in which artists engage with space and place has recently generated interest for geographers, who in turn are taking to art practice, 'creative geographies', as a means to understand and think about space and place differently, as well as the experiences, meanings and relationships associated with places (Hawkins 2011).

To explore perceptions of place through sensory impression, experience, imagination and memory, it was imperative that I became more than an impartial observer, and took an active role in the investigative process. In order to examine perceptions of place, one must be in the context of the surroundings. Ingold (2011) calls this the "dwelling perspective" advocating that since people are actively engaged with their environment, they are therefore very much an essential part of it. In this instance, my individual experiences in the park, form the content for my exploratory mapping exercises.

In assuming the role of data collector I recorded and reflected on each visit to the park. A collection of data came from these visits, enabling me to capture the information in tangible ways, as well as sourcing information from elsewhere to support my subjective, physical experiences.

Thus my data collection included the recording of scientific data, raw and indisputable, such as weather reports, including temperature, wind gusts, precipitation, as well as walking apps that logged the route I took and the length and duration of my walks (Figure 2). In addition to the scientific data, I noted sounds and smells, photographed and recorded video of the walks and collected manmade and natural artefacts that lay in my path, while keeping a journal of my emotional responses, or significant events. As Gibson suggests, "we all behave with respect to things we can look at and feel, or smell and taste, and events we can listen to" (2013).
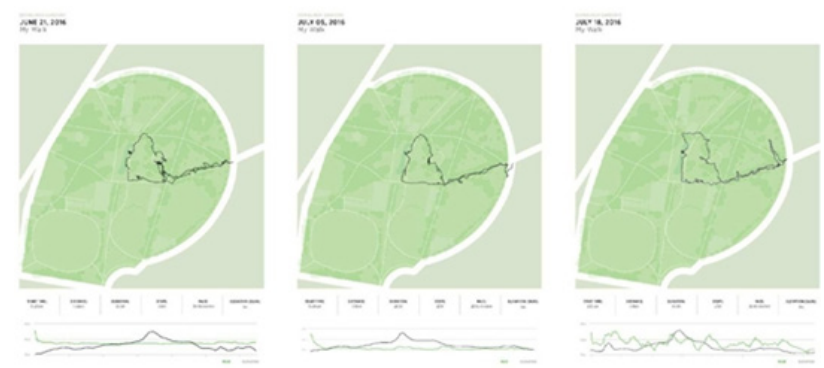

Figure 2. Sample of data collection of the Edinburgh Gardens, Joanna Gardener, 2016

\subsection{Making sense of the first visit}

The first walk through the park generated a lot of questions, and lay the groundwork for all future walks. This walk lasted for nearly 2 hours. Acutely aware of my surroundings, I was consciously tracking everything I could. I struggled to know where to begin; it was difficult to filter the mass of information. It was as if through the act of trying to be aware of the environment around me I experienced a sensory overload that in fact made me less aware. Intent on 'capturing' it all - the smells, touch, sounds, sights, I found I was unable to process the information or create a useful hierarchy for the individual sense impressions as they bombarded me.

As a designer who deals primarily with visual imagery, this conscious awareness of the senses made me want to examine the role they play in shaping our perception of place. Sensory perception is quite ambiguous, as the brain tries to link all these senses and information together to comprehend what is taking place at any given moment (SBS Insight 2015). While thirty percent of the brain's cortex is devoted to visual processing, only eight percent is used for touch and only three percent for hearing (Grady 1993). For those who lose a sense, the plasticity of the brain allows it to become rewired to compensate for that sense, bringing other senses to the foreground. This plasticity is another factor altering our perception and experience of the world (O'Connor 2012).

With all of these senses overlapping, competing for attention, I realised very quickly a need to filter the information. I decided to focus on walking the path in a manner that was less highly focused. Furthermore, the act of walking cleared my head, letting the environment reveal itself to me, and take shape as I walked the path. I took snapshots of moments or objects that grabbed my attention, be it something on the ground, the passing waft of a smell, a sudden sound that caught me off-guard, a colour, an object, a texture (Figure 3). I allowed the information to come directly to me rather than actively seek it. Not all of the senses were working at the same level, at the same time. Predictably my sight was the dominant sense. But there were moments when a slight wind would bring with it the smell of wet tanbark or carry the sound of a distant laugh. With that wind I would feel a crisp freshness in the air, and the senses would work together simultaneously, generating a fleeting 'moment' in time, embedding itself in my memory of the park on that day. These 'moments' were fragments of time, but collectively they gave me an overall impression and perception of the park.

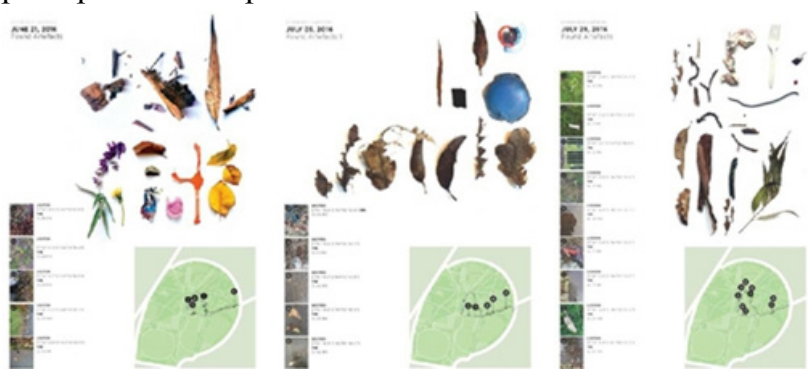

Figure 3. Sample of data collection of the Edinburgh Gardens, Joanna Gardener, 2016

I reflected on that first visit. I analysed the journey and sifted through the data I had collected. I reviewed my notes and photographs, which began to build a picture of the experience of place derived from this walk. I saw those special moments emerge from the data, as clearly as they were in my mind. I considered this data and filtered 
it, pulling it apart and putting it back together in smaller groups like piecing together a puzzle. This was my way of editing - selecting, filtering, categorising and organising data, much like the process of the cartographer.

\subsection{Reflections and Collections}

As the weeks progressed, my visits to the park became shorter. The shorter the walk, the clearer my impression became and the data collected was more focused. I continued to take in the sensory information as it came, rather than actively seek it out. This gave a truer reflection of the experience and also a more edited one. These sensory moments of smell, sound, touch and visuals were usually combined to create an overall (minor, yet potent) experience, such as the sound and feel of the rain falling, accentuating the smell of sweet, wet, freshly cut grass, that lay as visible clumps in a puddle on the path.

I established landmarks on my walks, places that stood out to me with each visit (Figure 4). As I continued these walks, my collection of landmarks would grow. What started as a naive first path, subconsciously continued to take hold, establishing my route for each visit; it became my loop. The initial purpose of taking the same path was to notice differences and compare each visit with the one before. The information I had gathered from the first visit, had (unexpectedly) laid the foundation for my base map, generating the background setting for my mapping exercises, allowing me to compare and analyse changes that had occurred from one visit to the next. This first path had become my primary, routine path, and it seemed wrong to change it. I had grown attached to my path and it now had significant meaning for me. So rather than change the path, my walks would expand and contract. I would visit the same landmarks, but not necessarily heed to the same exact path; this included visits to other locations within the park, shortcuts and 'paths of desire' as opposed to the designated path.
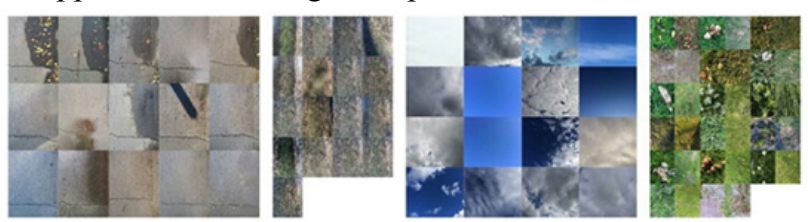

Figure 4. Sample of data collection of the Edinburgh Gardens, Joanna Gardener, 2016

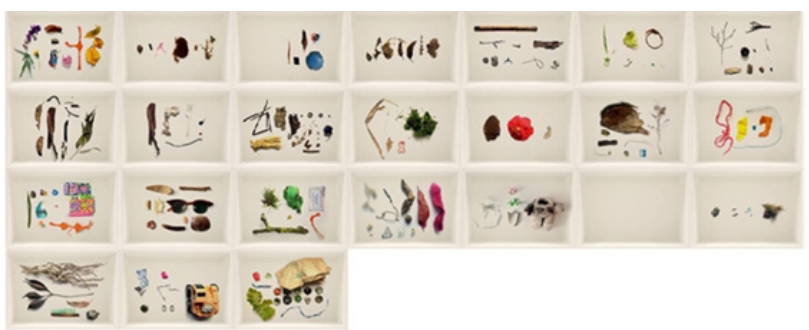

Figure 5. Cabinet of Curiosities: collections from the Edinburgh Gardens, Joanna Gardener, 2016

The collection of found artefacts also began to grow. Some days I would find objects of nature, but after a weekend I would find more personal objects that had been discarded, left behind, lost or forgotten. I would photograph these objects in location using geotagging and locating on the phone so I could record and retrieve the exact location where I found them. I grew curious about these objects and what they could tell me about the usage of the park, as they quickly started to form my own personal collection. I took home my collections to photograph, generating my own cabinet of curiosities (Figure 5). These objects together, represented a narrative of the park. It showed the seasons changing, the uses and functions of the park and memories of individual moments.

\section{Visualising the Data}

I needed to make sense of this data I had collected in a way that was familiar to me. I started by organising folders of comparison pictures, textures of bark, the path, the sky, the roundabout etc. I organized folders of my found objects. This filtering of information and organizing of data was my initial step in categorising the information I had accumulated over time, and through this process I became acutely aware of the artistic appearance of much of this collected data. I developed a filtered page of data of my mapped walks, which would become my brief for further exploratory mapping exercises. These pages included the weather and a collection of photographs that represented the mood and tone of the moment, from here I generated colour palettes of these individual experiences (Figure 6).
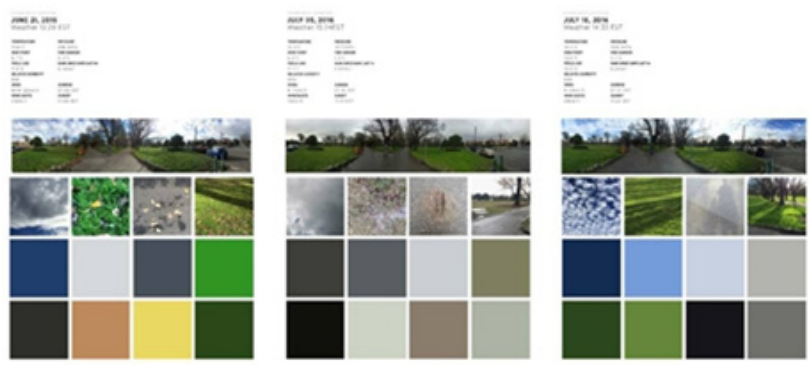

Figure 6. Sample of data collection of the Edinburgh Gardens, Joanna Gardener, 2016

My mapped routes alone created an overarching view of the park, an aerial view from above that didn't tell me much of what was happening on the ground level. Considering the walks themselves, each as an individual experience, I acknowledged the importance of the physical and personal point of view. We rarely experience the world from above as presented on most maps. On an everyday, human level we experience the world by moving through it. As we move through space, the change of environment brings with it a change of perception. Because we move through space as individuals, the world is seen through our own unique point of view, up close and personal, changing with each visit; hence the photographs, collections and sensory notes became pertinent data in regards to recording my experience of the place.

It was at this point of the mapping process, I started to see where and how this mapping exercise could take shape or form. I visualised these individual, embodied experiences of the park. This early stage of the mapping process, was 
now a moment to stop and reflect, draw inspiration from other artists and cartographers and consider how colour, mood, text, objects, temperature, duration etc. all became essential elements in the mapping process. Through this series of exploratory mapping exercises, the study endeavors to demonstrate the map's potential to arouse the senses, evoke emotion, and stimulate the imagination, bringing a different understanding of depth and meaning to places. This investigation has begun to inform the next stage of research, which takes this data and visually explores the interdisciplinary relationship of these distinct fields, seeking to understand the tipping point in regards to the boundaries of cartography and artistic expression (Figure 7, Figure 8 and Figure 9).

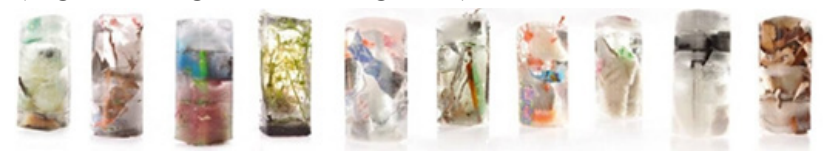

Figure 7. Space-time Cubes, Joanna Gardener, 2016 - 2017

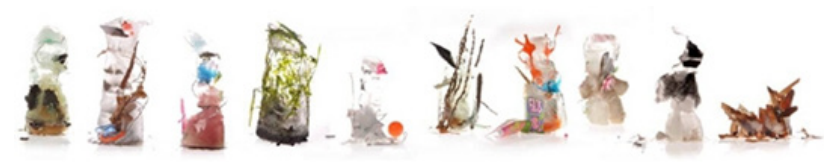

Figure 8. Space-time Cubes Melted, Joanna Gardener, 2016 2017

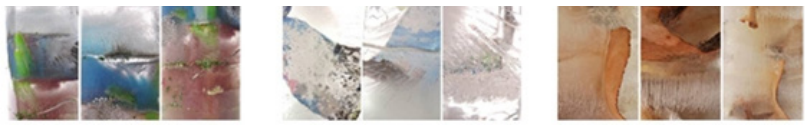

Figure 9. Space-time Cubes - Details, Joanna Gardener, 2016 2017

The short text of Richard Long's Notes on Maps (1994) offers a personal perspective of what constitutes a map, lending itself fittingly to these exploratory mapping exercises.

A map can be used to make a walk. A map can be used to make a work of art.

Maps have layers of information; they show history, geography, the naming of places. A map is an artistic and poetic combination of image and language.

For me, a map is a potent alternative to a photograph, it has a different function. It can show the idea of a whole work, not a moment.

A map can show time and space in a work of art.

Distance, the days of walking, the campsites, the shape of the walking, can be shown in one concise but rich image. In some of my works, I find the best places to realise particular ideas by first looking at a map.

A map can decide place and idea, either or both.

Maps can be read in many different ways, they are a standard universal language.

I like to think of my work on a map exists equally with all the other information on it.

On a long walk a map becomes a familiar, trusted object, something to look at endlessly, without boredom. I can look at the planned future and the completed past.

A map is light.

A map could save my life. (Long 2002)

\section{Conclusion}

This early exploratory stage of mapping, describes the journey from a designer's perspective through a practical and theoretical investigation into the crossover of scientific cartography, art and design, while seeking to understand the tipping point in regards to the boundaries of cartography and artistic expression. It demonstrates how the carto- graphic sciences, design thinking and artistic expression can inform one another to spark new ideas and generate new ways of thinking about approaches to cartography. Furthermore, it illustrates how the different disciplines engage with and understand space and place, interpreting the same information in ways that are unique to their areas of specialisation, which ultimately work together to generate our perceptions of the world around us.

\section{Acknowledgements}

I would like to thank Professor William Cartwright and Professor Lesley Duxbury for their thoughtful and inspiring discussions and advice. Their support and encouragement has helped me tremendously in this early stage of research.

\section{References}

Bertin, J \& Berg, WJ 2011, Semiology of graphics : diagrams, networks, maps, 1st edn., ESRI Press : Distributed by Ingram Publisher Services, Redlands, Calif.

Caquard, S 2011, 'Cartography I: Mapping narrative cartography', Progress in Human Geography, vol. 37, no. 1, pp. 135-144.

Caquard, S 2015, 'Cartography III: A postrepresentational perspective on cognitive cartography', Progress in Human Geography 39(2), pp. 225- 235.

Eno, B 2015, in BBC Music John Peel LectureBBC.

Gibson, JJ 2013, Ecological Approach To Visual Perception, Psychology Press, Milton, GB.

Gieseking, JJ 2013, 'Where We Go From Here: The Mental Sketch Mapping Method and Its Analytic Components', Qualitative Inquiry, vol. 19, no. 9, pp. 712-724.

Grady, D 1993, The Vision Thing: Mainly in the Brain, Discover Magazine, viewed September 21,

$<$ http://discovermagazine.com/1993/jun/thevisionthingma $227>$.

Hawkins, H 2011, 'Dialogues and Doings: Sketching the Relationships Between Geography and Art: Dialogues and doings', Geography Compass, vol. 5, no. 7, pp. 464478.

Insight, S 2015, Sensational: How much more can we use our senses?, viewed 21 September,

$<$ http://www.sbs.com.au/news/insight/tvepisode/sensatio nal>.

Kingsley, M 2015, 'In Praise of Doubt', in S Heller (ed.) The education of a Graphic Designer, Allworth press, 
New York, pp. 321-322. Long, R 2002, Richard Long : walking the line, Thames \& Hudson, London.

O'Connor, A 2012, Really? The Brain Gets Rewired if One of the Senses Is Lost, The New York Times, viewed September 21,

$<$ http://well.blogs.nytimes.com/2012/08/06/really-thebrain-gets-rewired-if-one-of-the-senses-is-lost/?_r=0) >. Robinson, AH 2010, The look of maps : an examination of cartographic design, 1st edn., ESRI Press, Redlands, Calif.

Rust, C 2007, 'Unstated Contributions - How Artistic Inquiry Can Inform Interdisciplinary Research', International Journal of Design, vol. 1, no. 3, pp. 69-76.

Solnit, R 2006, A field guide to getting lost, Penguin, New York.

Staines, J \& Clark, D 2005, The rough guide to classical music / edited by Joe Staines \& Duncan Clark, 4th ed edn., Rough Guides, London; New York.

Wood, D \& Fels, J 2008, The natures of maps : cartographic constructions of the natural world, University of Chicago Press, Chicago. 